\title{
Exclusive Breast feeding Practices among Yoruba and Hausa ethnic groups in South West Nigeria: a comparative Study
}

\author{
Joseph Sina $0^{1^{*}}$ \\ DOI: https://doi.org/10.17511/ijphr.2014.i1.03
}

1* Owoseni Joseph Sina, College of Medicine and Health Sciences, Afe Babalola University, Ado-Ekiti, Nigeria.

Introduction: Knowledge and attitude of mothers towards the practice of exclusive breast feeding is high, however, in spite of the advantages accrued to its practice, the practice of exclusive breastfeeding is low among breastfeeding mothers. This suggests that knowledge about exclusive breastfeeding does not translate to practice of it. This study examines the practice of exclusive breastfeeding among Yoruba and Hausa ethnic groups in Ile-Ife, South West, Nigeria comparatively. Methods: A structured questionnaire was administered to 400 breastfeeding mothers of Yoruba and Hausa respectively. Focus group discussions were held with both Yoruba and Hausa mothers and indepth interview with health officials in the Hausa and Yoruba communities. Results: Level of awareness of exclusive breastfeeding was found to be high among both categories of mothers ( $99.6 \%$ of Yoruba and $91-8 \%$ of Hausa mothers), the level of practice being higher amidst Yoruba (about 32\% than Hausa (26\%) mothers. Each of perception of effect of EBF on health of mothers and the effectiveness of EBF in spacing children $\left(X^{2}=.746, P=0.017\right)$ was found to be significant in influencing Hausa mothers' practice of EBF, but not significant for EBF for Yoruba mothers ( $X^{2}$ 12.955, $P=0.01$ ) but not for Hausa mother. A significant difference was found in the practice of $E B F$ between Yoruba and Hausa mothers $\left(X^{2}=56.282, P=0.000\right)$. Conclusion: Yoruba and Hausa mothers face significant challenges in a bid to exclusively breastfeed their babies. Efforts should be made to involve other bodies such as government, religious and civil bodies in campaign programs on EBF.

Keywords: Awareness, Attitude, Nigeria, Practice, Exclusive Breastfeeding

Corresponding Author

Owoseni Joseph Sina, College of Medicine and Health Sciences, Afe Babalola University, Ado-Ekiti, Nigeria. Email: owoshynah@yahoo.cor
How to Cite this Article

To Browse

Sina OJ. Exclusive Breast feeding Practices among Yoruba and Hausa ethnic groups in South West Nigeria: a comparative Study. Public Health Rev Int J Public Health Res. 2014;1(1):9-17. Available From

https://publichealth.medresearch.in/index.php/ijphr/ article/view/3

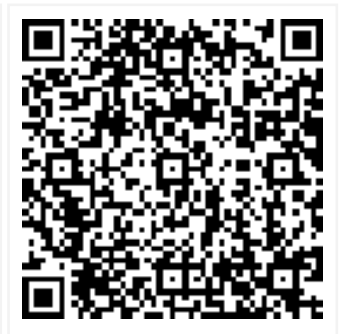

\section{Manuscript Received} 2014-04-17

Conflict of Interest No
Review Round 1 2014-04-25

Funding Nil

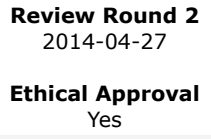

Review Round 3

Plagiarism X-checker $6 \%$
Accepted 2014-05-16

(C) 2014 by Owoseni Joseph Sina and Published by Siddharth Health Research and Social Welfare Society. This is an Open Access article licensed under a Creative Commons Attribution 4.0 International License https://creativecommons.org/licenses/by/4.0/ unported [CC BY 4.0]. 


\section{Introduction}

Contraceptive use is still low in many developing countries, including Nigeria, where $23.7 \%$ of currently married women had ever used one [1]. According to NDHS, knowledge of contraceptive methods is widespread in Nigeria, $72 \%$ of all women and $90 \%$ of all men knowing at least one method of contraception [2]. High fertility, poor maternal and child health are often symptoms of poverty [3], contributing to low use of contraceptives.

In West and Central Africa, the protection, promotion and support of exclusive breastfeeding is acknowledged as the single most critical strategy to achieve the Millennium Development Goals for the reduction of child mortality; however, the rate of exclusive breastfeeding in West and Central Africa (20\%) remains among the lowest in the world [4].

Breastfeeding also benefits the mother by helping the uterus to retract, which can reduce post partum blood loss, and delaying the return of menses, thereby preventing a subsequent closely spaced pregnancy [5]. Indeed, the length and nature of breastfeeding directly affect fertility, with the period of amenorrhea being longer, the longer she waits before introducing other foods and liquids.

One of the factors indicative of the likely success and adequacy of breastfeeding, as well as the effectiveness of lactational amenorrhea as birth control in early life, is the frequency of breastfeeding. UNICEF and WHO recommend that children should be exclusively breastfed during the first six months of life and that children be given solid or semi-solid complementary foods in addition to continued breastfeeding from age 6 months to 24 months (or more) when the child is fully weaned [1, 2].

Breastfeeding as a natural contraceptive practice of women in developing countries are critical, determinants of child survival, maternal reproductive health and population growth rates. Breastfeeding for the first two years of life and beyond protects the young child from infection, provides an ideal source of nutrients, is a costeffective and safe form of feeding, fosters motherchild bonding [2] and lowers the risks of early childhood deaths. In children not breastfed at all, the risk of early death from diarrhea, respiratory disease, and other common childhood illnesses rises dramatically compared with children who are exclusively breastfed [2].
Reducing child malnutrition is a key millennium development goal, as child nutrition and health produces a wide and diverse range of adverse economic and social consequences. Malnutrition is the leading factor of slow or inadequate growth. There are several conditions that lead to poor nutritional status of children: bad or inadequate feeding during early childhood, malabsorption of nutrients or the ability to use nutrients properly. Malnutrition substantially raises the risk of infant and child deaths, and increases vulnerability to a variety of diseases in later life. Poverty and malnutrition are persistent problems in Africa.

Poverty is a root cause of undernourishment and malnutrition. In particular, previous studies have identified the following as key determinants of child nutrition: per capita national incomes, women's education, variables related to health services, healthy environment and per capita national food availability [6]. Numerous factors contribute to the concept of poverty, including political, economic, social and cultural forces [7]. There are a lot of challenges that are facing the family planning services but though inspite of these challenges, family planning continues to be one of the best opportunities to improve the health of mothers and children throughout Africa.

Thus, for poor and developing countries, like Nigeria where the prevalence of breastfeeding as a contraceptive is low, appropriately managed breastfeeding should be a key component of reproductive health programs.

\section{Problems}

More harm has been done by developing countries in promoting the use of modern contraceptive at an early stage of child birth instead of emphasizing exclusive breastfeeding as a contraceptive method (which has been shown to be cost-effective in birth spacing). The net effect of this in the case of Nigeria is an unmet need [8] for family planning of all women at $16 \%$ ( $12 \%$ for spacing, $4 \%$ for limiting births).

This unmet need can easily be filled through the use of Lactational Amenorrhea Method (LAM). Achieving this will require a proper understanding of lactating mothers' knowledge, attitude, practice and perception on exclusive breastfeeding as a contraceptive method. Besides, the need for a study such as this devolves from MDG goal one that envisages the growth of LAM as a cost-effective contraceptive given its dual advantage. 
Furthermore, the study becomes apt in the context of [2 and 8] reporting of decline in the use of exclusive breastfeeding as a contraceptive in Nigeria. There is the need to understand the reason for such a decline when the thrust should be towards an increase in its adoption by all women. The findings of this research will no doubt fast track the development of intervention programmes that will improve the use of exclusive breastfeeding to meet the unmet needs for family planning in Nigeria. Thus the uniqueness of this study rests on the emphasis on exclusive breastfeeding as contraceptive aside from the general view of it as a nutritional and maternal health tool.

This study will therefore shed more light on the knowledge, attitude, practice and perception of lactating mothers as to the use of exclusive breastfeeding as a contraceptive. By so doing, the study outcome will contribute to policy formulation process in the area of population control in Nigeria and by extension to the development process.

\section{Method}

Mixed method of research that consists of a structured questionnaire, focus group discussion and in-depth interview was adopted. The study population consisted of breastfeeding Yoruba and Hausa mothers and health officials. Nurses attached to the maternity centers attended by the lactating mothers were also interviewed.

In the quantitative segment of this study, a structured questionnaire was adopted. The survey among Yoruba and Hausa breastfeeding mothers was carried out between June and July, 2012 at their respective houses. The Hausa were located at their Sabo. (Ilare Ward III of Ife central local government) in Ile-Ife while the Hausa in Modakeke were located in Ife East Local government (Ward III). The focus group discussion among Hausa and Yoruba breastfeeding mothers was carried out in June, 2012. The in-depth interviews with nurses was carried out in July, 2012 at two different maternity centres; comprehensive health centre, Sabo Ile-Ife (merses attending to Hausa) and comprehensive health centre, Itaasin, Modakeke (nurses attending to Yoruba).

\section{Sampling Procedure}

Respondents in the quantitative segment were recruited using different methods; this was influenced by the spatial population distribution of one of the tribes (Hausa) in the study.
Household census was carried out in the Hausa settlement, a total of 150 households were enumerated, and a mother was picked at random from each household in the Hausa settlement to represent women with reproductive age in the Hausa community. 'In the Yoruba community, a convenience sampling method was used to select participants in the study. Maternity centers and residential areas were visited in order to recruit mothers who are currently breastfeeding. Of this population 250 breastfeeding mothers who met the study inclusion criteria agreed to participate.

Attention was focused on mother's breastfeeding currently and who experience of breastfeeding (having more than one child), this helped in examining their experience about the practice of exclusive breastfeeding and breastfeeding imitation. Of the 400 nursing mothers who met the inclusion criteria, 367volunteer responded to the interviewer administered questionnaire. Thirty three breastfeeding mothers declined participation because of time constraint. Hence, the analysis was based on 367 valid responses, representing a response rate of 92 percent.

In the quantitative strand, a purposive sampling approach was used to recruit 7 breastfeeding mothers each from both Hausa and Yoruba nursing mothers of focus group discussion. Also, 2 nurses each form the maternity centers attended by the nursing mothers (Hausa and Yoruba) were purposively recruited for the in-depth interview. All of them honoured the invitation and participated actively in the focus group discussion and the indepth interviews respectively.

\section{Instruments}

Three research instruments of data collection of structured questionnaire, focus group discussion guide and in-depth interview were adopted to examine the level of awareness, attitude and practice of exclusive breastfeeding as a child rearing practice among Hausa and Yoruba mothers. A ninepage questionnaire designed in line with questions measuring awareness, attitude and practice using KAP research protocols. Prior to the main study, a pilot study was carried out among 25 women from both Hausa and Yoruba communities' recruited form Sabo (Hausa settlement) and Ojoyin Street in IleIfe.

This was to ensure that the instruments would be capable of eliciting useful and relevant information to the study. 
The first section of the questionnaire covered the respondents' socio demographic characteristics such as age, educational level, marital status, ethnic group, number of children, age of current child and monthly income. The second section featured questions on levels of awareness and economic ability of mothers towards the practice of exclusive breastfeeding. The third section examined the perceived influence of exclusive breastfeeding on the health of mothers. The fourth section was centered on the coping strategies of working mothers practicing exclusive breastfeeding. A total of 42 questions were asked targeting knowledge, attitude and practice of exclusive breastfeeding by nursing mothers.

Focus group discussions (FGD) were conducted among both Hausa and Yoruba mothers (women of reproductive age), lactating mothers and who have more than one child: Two FGDs were thus conducted. The participants were recruited using purposive sampling method and all met the inclusion criteria in the study.

\section{Method of data analysis}

The quantitative data was analyzed using the Statistical Package for Social Scientists (SPSS). Percentages were used to describe the demographic and socio-economic characteristics of the nursing mothers. The findings are presented as both discussions and tables. The in-depth interviews with health officials were conducted in English at the maternity centers. All other focus group discussions (with Hausa and Yoruba mothers) were held in the residential hall of the participants.

An FGD guide was used and the discussion focused on, knowledge, attitude and practice of exclusive breastfeeding and each of the FGDs explored the following main issues; the first events such as the first feeds, colostrums, exclusive breastfeeding, expression of breast milk, benefits and advantages of excusive breastfeeding, challenges faced and measures taken to combat the challenges of exclusive breastfeeding as a child rearing practice among Hausa and Yoruba lactating mothers.

Each FGD session had seven participants and was conducted in the local language of Hausa and Yoruba. Each FGD session was led by a trained research assistant with a recorder and lasted about one hour. Each of the discussions was also recorded on audio cassette tapes. The tapes were transcribed into English language. The discussions were held in July, 2012.

\section{Study Area}

The study was conducted in selected settlements of Hausa and Yoruba in Ile-Ife and Modakeke, Osun State. It extended to both educated and noneducated working and non-working nursing mothers of the selected settlements. Ile-Ife is situated in the tropical zone in West Africa with longitude 4.6E and $7.5 \mathrm{~N}$. Ile-Ife is divided into two local government area with headquarters in Ile-Ife central local governments carved out of Oranmiyan Local Government area by the Federal military government in May, 1989, The local government areas covers Ilare, Moore, Ilode, Iremo, Eleyele, Igboya, Adesanmi Estate, Ikoyi quarters, Sabo. The local government has eleven wards namely: Iremo I, II, III and I respectively, Ilare I, II, III and IV, Akarabata and Moore/Ojaja.

The people of Ile-Ife and Modakeke are predominantly farmers and traders. They cultivate markets that exist in the town such as Odo Ogbe market for food item traders, Orisunmibare market for plank sellers as well as numerous produce buyer stores. Ile-Ife is a mid-sized city and home to various social institutions such as Obafemi Awolowo University, and Obafemi Awolowo University Teaching Hospital Complex, dispensaries and health centres.

\section{Ethical consideration}

Participants were thoroughly intimated with the objectives of the study and their consent was received with majority of them giving verbal approval prior to the administration of any research protocols. All participants were also informed of their right to withdraw their participation in the study at any stage.

\section{Results}

\section{Respondents' profiles}

All the respondents are within the reproductive years of $15-39$ years. Their mean age is 28.87 , with standard deviation of $5.53 \%$. Most (97\%) of them are fully and currently married, while $1.3 \%$ of them are single mothers, $1 \%$ of them are separated and $0.5 \%$ of them are widowed. The study seeks to make comparisons on issues relating to the practice of exclusive breastfeeding between Yoruba and Hausa mothers. $250(62.5 \%)$ Yoruba mothers and $150(37.5 \%)$ Hausa mothers were covered. A summary of the survey respondents' profile can be seen in Table 1. 
Table-1: Percentage Distribution of Respondents across Age, Marital Status, Ethnic Group, Highest Educational Qualification and Religion

\begin{tabular}{|c|c|c|}
\hline Variable & Frequency & Percentage \\
\hline \multicolumn{3}{|l|}{ Age } \\
\hline $15-24$ years & 68 & 17.0 \\
\hline $25-34$ years & 256 & 64.0 \\
\hline $35-44$ years & 58 & 14.5 \\
\hline $45-54$ years & 7 & 1.8 \\
\hline Non-response & 11 & 2.8 \\
\hline Total & 400 & 100 \\
\hline \multicolumn{3}{|l|}{ Marital Status } \\
\hline Single & 5 & 1.3 \\
\hline Married & 388 & 97.0 \\
\hline Separated & 4 & 1.0 \\
\hline Widowed & 2 & 0.5 \\
\hline Non-response & 1 & 0.3 \\
\hline Total & 400 & 100 \\
\hline \multicolumn{3}{|l|}{ Ethnic Group } \\
\hline Yoruba & 245 & 61.3 \\
\hline Hausa & 148 & 37.0 \\
\hline Non-response & 7 & 1.8 \\
\hline Total & 400 & 100 \\
\hline \multicolumn{3}{|c|}{ Highest Educational Qualification } \\
\hline No formal education & 26 & 6.5 \\
\hline Primary education & 54 & 13.5 \\
\hline Secondary education & 172 & 43.0 \\
\hline Diploma & 2 & 0.5 \\
\hline NCE & 18 & 4.5 \\
\hline B.Sc./B.A. & 32 & 8.0 \\
\hline OND & 9 & 2.3 \\
\hline HND & 23 & 5.8 \\
\hline M.Sc./M.A. & 7 & 1.8 \\
\hline Quoranic school & 54 & 13.5 \\
\hline Non-response & 3 & 0.8 \\
\hline Total & 400 & 100 \\
\hline \multicolumn{3}{|l|}{ Religion } \\
\hline Christianity & 183 & 45.8 \\
\hline Islam & 215 & 53.8 \\
\hline Others & 1 & 0.3 \\
\hline Non-response & 1 & 0.3 \\
\hline Total & 400 & 100 \\
\hline
\end{tabular}

Source: Fieldwork, 2012 Among the nursing mothers who were interviewed the mean age is 26.5 years. The mean age of the health officials was 37.6years: at the time of the focus group discussion all the nursing mother were currently breastfeeding their children and they had more than one child. Majority of them were able to define and describe exclusive breastfeeding correctly, though there are variations in their level of experience

\section{Knowledge and Awareness of Exclusive Breastfeeding}

In both categories, most of the mothers have heard about exclusive breastfeeding $(99.6 \%$ of Yoruba mothers; $91.8 \%$ of Hausa mothers) However, the few that have not heard about exclusive breastfeeding attributed it to barrier in language especially the Hausa mothers, some of the participants in the Focus group. Discussion in both categories confirmed their awareness above exclusive breastfeeding:

We have all heard about EBF and it Means giving the baby breast milk without water or food for six months (Hausa and Yoruba mothers)

Although there were variations in their sources of information about exclusive breastfeeding. Most $(94.3 \%)$ of them got the information in a health facility (government or private hospital, or health centre). Few of them (3.4\%) got the information from friend or relatives, $1.8 \%$ of them from a faithbased organization (church or mosque) and $0.5 \%$ of them from other sources. Similarly, the focus group discussion revealed that:

We got to know about exclusive breastfeeding from the maternity centers, mission houses where we delivered our babies (Yoruba mothers)

We got to know about exclusive breastfeeding form our friends. (Hausa mothers)

Table 2: Knowledge and Awareness of Exclusive Breastfeeding

\begin{tabular}{|c|c|c|}
\hline variable & Frequency & $(\%)$ \\
\hline \multicolumn{3}{|l|}{ Having Knowledge About Exclusive Breastfeeding } \\
\hline Yes & 383 & 96.7 \\
\hline No & 13 & 3.3 \\
\hline \multicolumn{3}{|l|}{ Source of Information } \\
\hline Government Hospital & 252 & 63.0 \\
\hline Private hospital & 26 & 6.5 \\
\hline Health centre & 86 & 21.5 \\
\hline Family member & 8 & 2.0 \\
\hline Friend/Relative & 5 & 1.3 \\
\hline Church & 3 & 0.8 \\
\hline Mosque & 4 & 1.0 \\
\hline Others & 2 & 0.5 \\
\hline \multicolumn{3}{|l|}{ The Understanding of Exclusive Breastfeeding } \\
\hline $\begin{array}{l}\text { Give breast milk alone to infants without other fluids } \\
\text { for } 6 \text { months }\end{array}$ & 317 & 92.8 \\
\hline Give breast milk and other fluids for 6 months & 5 & 1.3 \\
\hline Give breast milk and other fluids for 4 months & 1 & 0.3 \\
\hline
\end{tabular}




\begin{tabular}{|l|l|l|l|}
\hline Give breast milk and formula for 6 months & 12 & 3.0 \\
Give breast milk and formula for 4 months & 1 & 0.3 \\
\hline Benefits of Exclusive Breastfeeding & 107 & 26.8 \\
\hline Nutrition & 7 & 1.8 \\
Child spacing & 2 & 0.5 \\
Economic & 219 & 54.8 \\
Protection of infant from illness & 51 & 12.8 \\
\hline
\end{tabular}

\section{Source: Fieldwork, 2012}

\section{Breastfeeding practices}

In both categories (Hausa and Yoruba mothers) there is high level of awareness of exclusive breastfeeding ( $99.6 \%$ of Yoruba mothers; $91.8 \%$ of Hausa mothers) and the intention of the mothers to breastfeed their babies up to year very among the two groups ( $68 \%$ of Hausa mother and $72 \%$ Yoruba mothers).

However, the practice of exclusive breastfeeding vary among the two categories (26\% of Hausa mothers and (32\%) of Yoruba mothers):

Breastfeeding initiation after birth vary among the mothers, most $(73 \%)$ of the mothers began breastfeeding hours after delivery, while $13 \%$ of them began days after delivery and $14 \%$ of them began breastfeeding about a month

\section{Table-3: Exclusive Breastfeeding Practices}

\begin{tabular}{|c|c|c|}
\hline Variable & Frequency & $(\%)$ \\
\hline \multicolumn{3}{|c|}{ How long after birth did you breastfeed your baby? } \\
\hline Hours & 279 & 69.8 \\
\hline Days & 48 & 12.0 \\
\hline Month & 54 & 13.5 \\
\hline Cannot remember & 19 & 4.8 \\
\hline \multicolumn{3}{|c|}{$\begin{array}{l}\text { In the first three days after delivery, was your child given anything apart } \\
\text { from breast milk }\end{array}$} \\
\hline Yes & 85 & 21.3 \\
\hline No & 309 & 77.2 \\
\hline No Response & 6 & 1.5 \\
\hline \multicolumn{3}{|c|}{ How frequently do you breastfeed your baby } \\
\hline Hourly & 26 & 6.5 \\
\hline On Demand & 281 & 70.3 \\
\hline When I am free & 13 & 3.3 \\
\hline Others & 77 & 19.3 \\
\hline \multicolumn{3}{|c|}{ Ever Received Any Information About Exclusive Breastfeeding } \\
\hline Yes & 383 & 95.8 \\
\hline No & 13 & 3.3 \\
\hline \multicolumn{3}{|l|}{ Ever Exclusively Breastfed Your Child } \\
\hline Yes & 301 & 75.3 \\
\hline No & 89 & 22.3 \\
\hline
\end{tabular}

\begin{tabular}{|l|l|l|}
\hline \multicolumn{2}{|l|}{ Are You Exclusively Breastfeeding your child? } \\
\hline Yes No & $\begin{array}{l}\text { 749 } \\
\text { Who Influenced Your Decision? }\end{array}$ & $\begin{array}{l}79.8 \\
18.5\end{array}$ \\
\hline $\begin{array}{l}\text { Husband } \\
\text { Mother-In-Law } \\
\text { Self } \\
\text { Others }\end{array}$ & 61618399 & 15.31 .545 .824 .8 \\
\hline
\end{tabular}

\begin{tabular}{|c|c|c|}
\hline Variable & Frequency & $(\%)$ \\
\hline \multicolumn{3}{|l|}{ Having Knowledge About Exclusive Breastfeeding } \\
\hline Yes & 383 & 96.7 \\
\hline No & 13 & 3.3 \\
\hline \multicolumn{3}{|l|}{ Source of Information } \\
\hline Government Hospital & 252 & 63.0 \\
\hline Private hospital & 26 & 6.5 \\
\hline Health centre & 86 & 21.5 \\
\hline Family member & 8 & 2.0 \\
\hline Friend/Relative & 5 & 1.3 \\
\hline Church & 3 & 0.8 \\
\hline Mosque & 4 & 1.0 \\
\hline Others & 2 & 0.5 \\
\hline \multicolumn{3}{|l|}{ The Understanding of Exclusive Breastfeeding } \\
\hline Give breast milk alone to infants without other fluids & 317 & 92.8 \\
\hline for 6 months & 5 & 1.3 \\
\hline Give breast milk and other fluids for 6 months & 1 & 0.3 \\
\hline Give breast milk and other fluids for 4 months & 12 & 3.0 \\
\hline Give breast milk and formula for 6 months & 1 & 0.3 \\
\hline Give breast milk and formula for 4 months & & \\
\hline \multicolumn{3}{|l|}{ Benefits of Exclusive Breastfeeding } \\
\hline Nutrition & 107 & 26.8 \\
\hline Child spacing & 7 & 1.8 \\
\hline Economic & 2 & 0.5 \\
\hline Protection of infant from illness & 219 & 54.8 \\
\hline Others & 51 & 12.8 \\
\hline
\end{tabular}

\section{Source: Fieldwork, 2012}

Perceived influence of exclusive breastfeeding on health of mothers In contrast to many assertions that exclusive breastfeeding influenced negatively, the health of mothers practicing it; evidence have shown that nursing mothers disagree about such comments concerning exclusive breastfeeding such as; loss of weight, pain on the nipple, sagging. however, frequency of mothers who agree that practices of exclusive breastfeeding demands high rate of nutrition (97.9\%). Most $66.7 \%$ of the mothers disagreed that EBF can lead to loss of weight, $55.2 \%$ of them disagreed that it can alter the sleeping pattern of the mothers, here, mothers ascents that they prefer to sleep on the same bed with their infants in order to make breastfeeding easier. 
Table 4. the experience of both Hausa and Yoruba mothers who participated in the focus group discussion also revealed that:

We do not experience any health challenge as a result of the practice of exclusive breastfeeding.
We just want to implore our husbands to provide enough feeding $s$ that our breasts milk will be able to flow well.

Table 4: Respondents' Opinions about Effects of EBF on health of mothers.

\begin{tabular}{|l|l|l|l|l|}
\hline & \multicolumn{1}{|c|}{ Strongly Disagree } & Dis agree & \multicolumn{1}{|c|}{ Agree } & \multicolumn{1}{|c|}{ Strongly Agree } \\
\hline It can lead to loss of weight & $138(34.5)$ & $129(32.5)$ & $62(15.4)$ & $71(176)$ \\
\hline It makes mothers to be hungry often & $4(1 / 0)$ & $44(11.1)$ & $97(34.1)$ & $254(63.8)$ \\
\hline It can alter the sleeping pattern of mothers & $51(12.5)$ & $169(42.6)$ & $107(26.7)$ & $73(18.1)$ \\
\hline It can inflict some pains or discomfort on the mother (nipple pain) & $87(21.7)$ & $179(45.1)$ & $95(23.9)$ & $38(9.3)$ \\
\hline It can result into sagging of breast & $75(18.7)$ & $159(40.3)$ & $85(21.0)$ & $81(20.3)$ \\
\hline
\end{tabular}

\section{Source: Fieldwork, 2012}

\section{Discussion}

Comparative evidence from this study showed a high level of awareness about exclusive breastfeeding, in both categories, most of the mothers have heard about exclusive breastfeeding (99.6\% of Yoruba mothers; $91.8 \%$ of Hausa mothers). A previous study by Agunbiade in 2012 in Ile-Ife also revealed a high level of awareness of exclusive breastfeeding [9] by nursing mothers (94\%) also in Davies Adetugbo's study on awareness and relevance of colostrums among nursing mother in rural Yoruba community in Nigeria [10]. (82\%) However, the practice of EBF in the study area is relatively low among the Hausa and Yoruba nursing mothers. This may be hinged on some cultural beliefs associated with child birth and rearing practices among the people [11].

The Nigerian Demographic Health survey (NDHS), 2008 showed that only $13 \%$ of a children below six months are exclusively breastfed while $87 \%$ of Nigerian infants below six months receive complementary liquids or foods [12]. The influence to breastfeed exclusively is major factor to be considered, the role of the significant others on the nursing mothers is very important [13], evidence in this study showed that Hausa mothers' significant orders have great influence on the attitude of mothers to breastfeed exclusively as all of them $(100 \%)$ chose to practice Exclusive Breastfeeding based on the influence of significant others.

This suggests that the influence and decision to practice exclusive breastfeeding was culturally based.
The family structure, in the form of extended families, was also considered as supportive in promoting the practice of exclusive breastfeeding as claimed by Senaiumhe's study [14].

Also, higher proportion (36.1) of Hausa mothers gave their child days after delivery, while only $12.5 \%$ of the Yoruba mothers did. This supports the erroneous belief of a women's breast milk not being good and not sufficient enough could be attributed to mothers' giving other food supplement apart from breast milk [15]. This finding supports Jellife's position that some grandmothers felt that the early introduction of complementary feeding and herbal concoction would be better than breast milk only [16].

\section{Conclusion}

Awareness and attitude of mothers towards the practice of exclusive breastfeeding does not translate into higher use. The implication of this is that there is a need to translate positive knowledge, positive attitude into positivepractice, to increase the practice of exclusive breastfeeding among mothers. Different factors including education, culture, age of respondents and monthly income influenced the attitude of mothers towards the practice of exclusive breastfeeding.

There is an urgent need to modify existing policy on exclusive breastfeeding to include collaboration between government and other religious bodies to help in disseminating information about the practice and benefits that are related to the practice of exclusive breastfeeding. 


\section{Reference}

01. National population Commission (NPC). Nigeria Demographic and Health Survey National Population Commission and ICF Macro, Abuja, Nigeria. Nigeria ICF Macro. 2009.

Cited from: [Article] [Crossref]

02. Nigeria Demographic and Health Survey, 2008. Cited from: [Article] [Crossref]

03. Mc Neilly AS, Howie PW, Glassier A. Lactation and the return of ovulation, In Natural Human Fertility, Social and Biological Determinants, Edited by Diggory $P$, Potts $M$, Teper $S$ Proceedings of the Twenty-third Annual Symposium of the Eugenics Society, London, Basing Stoke. UK- Macmillian Press. 103-117. [Crossref]

04. Bhuyan A, Borda M, Winfrey W. Making family planning part of the PRSP process- A Guide for Incorporating Family Planning programs Into Poverty Reduction Strategy papers. Washington DC- Constella Future, USAID/Health Policy Initiative. 2007;19.

[Crossref]

05. Ogbe JO. Exclusive breastfeeding and children immunization as demographic determinants of child mortality in Delta State. Pakistan Journal of Nutrition. 2008;7(1)35-39.

[Crossref]

06. Stern JM, Konner M, Herman TN, Reichlin S. Nursing behavior, prolactin and postpartum amenorrhoea during prolonged lactation in American and !Kung mothers. Clin Endocrinol (oxf). $1986 ; 25 ; 247-258$.

[Crossref]

07. Campbell OMR, Gray RH. Characteristics and determinants of postpartum ovarian function in women in the United States. Am J Obstel Gynecol. 1993;169;55-60.

[Crossref]

08. Smith DP, Benoit F. Correlates of breastfeedingA critical review of available information. World Health Statistics Quarterly. 1985;35;92-116. [Crossref]

09. Afifi M. Lactational amenorrhoea method for family planning and women empowerment in Egypt. Singapore Med J. 2007;48;758-762.

[Crossref]
10. Aguirre GP, Palloni A, Jones RE. Effects of lactation on postpartum amennorrhoea- Reestimation using data from a longitudinal study in Guatemale. Pop stud (Camb). 1998;52;231248.

[Crossref]

11. Amperire IP. Perception and Knowledge on Exclusive breastfeeding Among Women Attending Antenatal and Postnatal Clinics. 2008;27-28.

[Crossref]

12. Rossetta L. Aetiological approach of female reproductive physiology in lactational amenorrhoea. J Biosoc Sci. 1992;24;301-315. [Crossref]

13. Short RV, Lewis PR, Renfree MB, Shaw G. Contraceptive effects of extended lactational amenorrhoea- Beyond the Bellagio Consensus Lancet. $2011 ; 337 ; 715-717$.

[Crossref]

14. Senaiumhe $A E$, Oviawe $O$. The changing pattern of post partum sexual abstinence in a Nigerian Rural Community. Soc Sci Med. 1986;23(7)683686.

[Crossref]

15. Vekemans M. Postpartum contraception, The lactational amenorrhea method. Eur J Contracept Reprod Health Care. 2007;2;105111.

[Crossref]

16. Vestermark V, Hoydall CK, Plenov G, Birch M. Postpartum amenorrhoea and breast-feeding in a Danish sample. J Bio Soc Sci. 1994;26;1-7. [Crossref]

17. Brown KH, Dewey KG, Allen LH. Complementary Feeding of Young Children in Developing Countries- A review of current scientific knowledge. WHO/UNICEF. 1998. [Crossref] 